\title{
Rejunevating Teacher Leadership Capacity through an in-service Training Program Focusing on Active Learning: A Case Study
}

\author{
Norma Ghamrawi ${ }^{1}$, Noha Al-Hassan ${ }^{2}$
}

\begin{abstract}
${ }^{1}$ Professor of Educational Management \& Leaadership- Faculty of Education- Lebanese University- Beirut, Lebanon ${ }^{1}$ Doctoral Candidate in Educational Administration, Doctoral School of Literature, Humanities \& Social Studies, Lebanese University
\end{abstract}

\begin{abstract}
This study investigated the impact of an intervention program on developing teacher leadership skills by developing teachers' capacities on shifting classrooms from teacher-centered to student-centered learning environments. Findings of this paper are part of a larger study that employed the action research methodology, and was carried out over the course of one academic year in a K-12 private school in Mount Lebanon. The sample involved 15 teachers and data was collected through (1) a classroom observation tool; and (2) a teacher leadership survey. Data collection instruments were administered before and after the intervention program that aimed at leveraging the repertoire of classroom practices into student-centered learning environments. Microsoft Excel was employed to calculate descriptive statisctics. Results showed that the intervention had a slight, yet appreciable impact on the teaching-learning environment; and supported the development of teacher leadership skills.
\end{abstract}

Keywords: Student-Centered Classrooms, Teacher Leadership, School Improvement, Active Learning

\section{Introduction}

\subsection{The Problem}

The rapid changes and increased intricacy of today's world have presented new challenges and put great demands on our education systems (Schleicher, 2015). Globalization and knowledge economy have enforced the acquisition of $21^{\text {st }}$ century skills (Fullan \& Langworthy, 2013). According to Williams (2011), classrooms should contribute to developing the student's personality so that he/she can face challenges and own the wisdom to hold responsibility, reflect, evaluate, watch for hidden details, make decisions, communicate effectively and innovate.

Traditional teacher-centered classrooms generally generate passive students who lack the skills required for effective involvement in the current social and economic world (Schleicher, 2015). Teachers have been identified as the first most important factor in structuring student-centered classrooms where students are cognitively and socially active (Wiederman, 2015). On the other hand, studentcentered classrooms emphasize cooperative learning and take students to higher levels of critical thinking, problem solving, improvement of attitude to learn and an increase in overall attendance thus reinforce $21^{\text {st }}$ skills (Overby, 2011; Wiederman, 2015).
However, many students all over the world are still receiving their education in teacher-centered classrooms and thus fail at meeting the current century challenges (Schleicher, 2015). Mizell (2010) argued that professional development is required for school systems to strengthen teachers' performance level and reinforce student-centered classrooms. Overby (2011) discussed that the success of studentcentered approach is directly related to teacher leadership.

In parallel, McCarthy (2015) viewed that the leadership style of the teacher identifies the extent to which his/her classroom would serve as a studentcentered environment. According to Sergiovanni \& Starrat (2007), teacher leaders believe that students are workers involved in the production and experimenting of knowledge, setting the plans, sharing, making decisions and working with classmates.

One of the researchers was an elementary school teacher in a private school located in Mount Lebanon. For anonymity purpose, the school is termed School $\mathrm{X}$ throughout this paper. Teacher-centered approach was highly prevailing in the school. This practice resulted in having classrooms with passive students whose roles were very limited. In coordination with School X administration, an outsourced intervention

This article is published under the terms of the Creative Commons Attribution License 4.0 Author(s) retain the copyright of this article. Publication rights with Alkhaer Publications. Published at: http://www.ijsciences.com/pub/issue/2019-10/ DOI: 10.18483/ijSci.2212; Online ISSN: 2305-3925; Print ISSN: 2410-4477 
program was conducted over a whole school year, with the aforementioned researcher being an assistant.

The decision was made to develop teachers' skills so that they could lead student-centered classrooms providing students with ample opportunities to be actively involved in their own learning. The intervention program was implemented by an external body of trainers, and it targeted Grades 1-3 teachers. Active learning was the foundation stone of the program.

This study attempted to investigate the degree to which the intervention program has turned teachercentered classrooms into student-centered environments, noting the effect that the program has had on teachers' leadership practices; as the literature cites connection between teachers leading student-led classrooms and teacher leadership skills (Ghamrawi, 2010; Northouse, 2013).

\subsection{Purpose of the Study}

The purpose of this study was to investigate the impact a capacity-building intervention program for teachers on leading student-centered classrooms had on turning main-subject classrooms (English Language, Arabic Language, math, science) of cycle one (grades one, two, three) from teacher-centered to student-centered environments. In addition, the study attempted to explore the degree to which the intervention program impacted teacher leadership skills.

\subsection{Research Questions}

This study was guided by the following research questions:

1- How would an intervention program contribute to shifting classroom practice from being teacher-centered to become student-centered?

2- How do the leadership practices of teachers evolve during the course of the intervention?

\subsection{Significance of the Study}

Student-centered classrooms that ensure the child's active involvement in his/her learning and underpin $21^{\text {st }}$ century skills have become a major component of education systems (Fitzsimmons, 2011; Overby, 2011; Wiederman, 2015). However, many schools are still behind in recognizing the significance of this practice (Schleicher, 2015). Unfortunately, rote learning and passive students are still there. It is of utmost importance to shed light on this topic. Hence, this part of the study reported the outcomes of an intervention program that sought the evolution of teaching practices towards developing studentcentered environments.
Besides, the literature suggests that teacher-centered classrooms are induced by weak teacher leadership (Northouse, 2013). A small body of literature has highlighted the link between teacher leadership practice and student-centered classroom; arguing that student-centered classrooms entail a more active teacher leadership role. The researcherers decided to approach the problem in a relatively different way, attempting to explore how teachers' leadership practices evolved as a result of a capacity-building intervention program for teachers that aimed at supporting them in activating students' roles within student-centered classrooms.

\section{Review of Related Literature}

\subsection{Student-Centered Classroom}

Student-centered classroom is the autonomous instruction that involves self-directed learners who not only participate in what, how and when to learn, but also construct their own learning experiences (Ahmed, 2013). It is the context where information is not synonymous to knowledge, so the key is a deeper understanding that allows for application, critical thinking and problem solving (Wiederman, 2015).

Phipher (2002) stated that a student-centered classroom is a community of learners where such communities emphasize cooperation and encourage learning by working and helping others learn. Overby (2011) also introduced student-centered learning as the way that "brings the classrooms and the students to life where the teacher is considered a guide on the side guiding students to meet the goals that have been made by the teacher and the students" (p. 1).

In the student-centered classroom leadership is shared, and all students have the opportunity to be part of the management of the classroom (Williams, 2011). Rules are developed by the teacher and students; thus, discipline comes from the self (Garrett, 2008). Partnerships are formed with community groups to enrich the learning opportunities for students (Garrett, 2008; Williams, 2011). This is parallel to Fenner, Mansour, \& Sydor (2010) who argued that differentiation in instruction within the student-centered classroom leads to success.

Phipher (2002) asserted that student-centered classroom approach is best applied through cooperative learning that extends beyond group work. Cooperative learning provides structure for every group member to hold an important role or responsibility in the group (Phipher, 2002). Attard, Ioio, Geven \& Santa (2014) argued that there is no one universal definition of student-centered learning. However, by considering the above definitions and discussions, it can be assumed that many of the 
student-centered classroom components are part of the active learning that provides students with opportunities to reflect, evaluate, synthesize and communicate the information in class (Fink, 2013).

\subsection{Active Learning Approach}

Few decades ago, critical changes to the concept of education were introduced. Schools had to look beyond the passive learning approach so that learning could activate students' roles (Berek, 2013). Bonwell \& Eison (1991) defined active learning as the activities that require students to do them and think about what they are doing. Empirical evidences in research have proved that active learning approach where teachers take the role of facilitators and consider students' needs and learning styles yields better outcomes (Patton, 2015).

Williams (2011) considered that active learning can't be applied through lecturing where students repeat the information presented to them; it is rather implemented through cooperative learning in which students explore the meaning of the information and reflect upon it. Reflection and reasoning are discussed by Colthorpe, Chen \& Zimbardi (2014). Colthorpe et al. (2014) concluded that reasoning and reflection by students can be reinforced by having them evaluate peer's performance and provide feedback.

In the same manner, wonderment questions that encourage the students to hypothesize, predict and generate explanations (Craig \& Deretchin, 2010; Fitzsimmons, 2011) and class participation (Czekanski \& Wolf, 2013) are evidences pf active learning. The International Baccalaureate Organization (IBO) linked active learning to inquiry and identified a set of indicators that were classified into three major fields: student, teacher and classroom environment. An active learning approach is implemented when students are given the opportunity and guided to ask investigation questions, link new concepts to their existing knowledge, communicate, infer and deduce conclusions (IBO, 2008). Students will be empowered to do so when their teachers provide the required materials, demonstrate, model, supervise, guide, motivate and give learners the chance to observe, experience and investigate within a supportive classroom environment (IBO, 2008).

To sum, active learning is not limited to gaining information; it rather helps develop students' skills and prepare the student to take an active role in the society (IBO, 2008; Williams, 2011; Berek, 2013; Colthorpe et al., 2014; Patton, 2015). Hence, the implementation of active learning approach requires teacher leaders (Northouse, 2013) who empower students and refuse to have them as passive learners (Ghamrawi, 2013). Similarly, Sergiovanni \& Starrat (2007) argued that teacher leaders view students as workers involved in the production and performance of knowledge and consequently develop a community of learners.

\subsection{Teacher Leadership}

Donaldson (2006) discussed two types of teacher leaders: the formal teacher leaders who are formally appointed, such as department chairs, team leaders or association officers and the informal teacher leaders who naturally emerge among their colleagues as trusted and respected catalysts. Informal teacher leaders are teachers who have an established history of contribution to the school, students, community and colleagues (Donaldson, 2006). Chin (2001) added to the aforementioned tasks that they are teachers who give the time and the encouragement for their students to think deeply and ask wonderment questions - questions that foster analysis, discussion, hypotheses, prediction and reasoning. In the same context, Lumpkin, Claxton \& Wilson (2014) considered teacher leaders as innovative, collaborative and trustworthy facilitators of learning who use data and other evidences in making decisions and solving problems within a studentcentered classroom environment. They involve students in all classroom practices, expose them to situations where they have to find solutions and ask them to evaluate others (Xu \& Patmor, 2012). Teacher leaders are expected to commit to ongoing professional development. Yildirim (2013) recommended the use of portfolio as it assists teachers to become aware of their personal and professional development, provides feedback about their performance and requires reflection.

Existing literature presented two major directions for cultivating teacher leadership. First, a huge body of research has concluded that all the promoting teacher leadership practices could be accomplished through conducting action research (Pimenta, 2005; Razfar, 2011). Second, other researchers argued that the school leadership impacts would either reinforce or deter teacher leadership skills. Sergiovanni \& Starratt (2007) stated that teacher leadership can be emphasized within the distributed leadership across the school. Teachers do not become leaders on their own. As such, school systems and good mentors are needed to help teachers develop their strengths and believe strongly in their leadership potentials (Sergiovanni \& Starratt, 2007).

Teachers' participation in decision-making on the school wide level might have significant contribution for they are the individuals in contact with the whole learning-learning process (Ghamrawi, 2013). In 
parallel, Berry, Daughtrey, \& Wieder (2010) claimed that when teachers are empowered as instructional leaders and decision-makers, students and the schools they attend will benefit.

In a professional learning community, teachers and other staff members are supported and encouraged to go professionally as leaders (Harris, 2010). In parallel, Spillane and Diamond (2007) argued that teachers should be given opportunities to develop as leaders to cultivate their leadership capacity, build professional community and gain the respect of their colleagues. The subject leader has a major role in developing teacher leadership (Ghamrawi, 2012).

\subsection{Conceptual Framework}

\section{Components of Teacher} Leadership

\begin{tabular}{|c|c|}
\hline Empowerment & Trial and Error \\
\hline $\begin{array}{c}\text { Professional } \\
\text { Development }\end{array}$ & Inspiration \\
\hline \hline $\begin{array}{c}\text { Reflection on } \\
\text { Achievement }\end{array}$ & $\begin{array}{c}\text { Task } \\
\text { Delegation }\end{array}$ \\
\hline $\begin{array}{c}\text { Interaction } \\
\text { Thared Decision } \\
\text { Making }\end{array}$ & Collaboration \\
\hline
\end{tabular}

Figure 1. Conceptual framework of the related literature

Figure 1 shows the connection among the literature reviewed elements that relate to this part of the study. Two types of arrows were used to show the link: the solid arrows labeled as (a) and (b) and the dotted arrows labeled as (1) and (2).

The solid arrows represent the link between teacher leadership and student-centered classrooms as discussed in literature. Since the definition of teacher leadership remains varied, the basic components that a teacher leader should have were derived from the existing literature. As shown through solid arrow (a), empowerment, trial and error, professional development, inspiration, reflection on achievement, task delegation, interaction, trust, shared decisionmaking and collaboration form the profile of a teacher leader. Hence, solid arrow (b) illustrates that a teacher leader who empowers, trusts, inspires and delegates tasks to his/her students (Sergiovanni \& Starrat, 2007); relies on trial and error method collecting data and evidences on practice (Lumpkin et al., 2014); shares in decision making in the school and involves his/her students in classroom decisions (Spillane \& Diamond, 2007; Berry et al., 2010; Harris, 2010; Ghamrawi, 2013); interacts and collaborates with colleagues and administrators ( $\mathrm{Xu}$ \& Patmor, 2012); reflects on practices and asks students to reflect and evaluate (Colthorpe et al., 2014); commit to continuous professional development and research activity (Pimenta, 2005; Razfar, 2011; Yildirim, 2013) is capable of running a student-centered classroom.
The abovementioned practices of a teacher leader align with the active learning approach that leads to a student-centered classroom. As such, teacher leaders have the skills and the capabilities to activate students' roles through engaging them in learning activities that develop their high-order thinking skills (Fitzsimmons, 2011; Colthorpe et al., 2014) and arouse their curiosity and inquiry mindset (IBO, 2008).

Therefore, the solid arrows clarify the direction that the mentioned elements follow as per literature. The dotted arrows, however, show the backward direction that the researcher attempted to investigate in the study. Dotted arrows (1) and (2) refer to the extent to which training teachers on implementing active learning within student-centered classrooms would impact their leadership skills.

\section{Methodology}

This study is part of a larger case-study that employed mixed methods. The quantitative method was employed for addressing the research questions selected for this particular study. 


\subsection{The Sample}

School $X$ administration and the participant researcher decided to address the problem of having teacher-centered classrooms through the action research approach. The decision was made to invite a well-known professional development team to carry out the intervention program. As the team assistant, the researcher had the privilege to attend all the conducted workshops and training sessions and was involved in the whole intervention process.

The intervention program targeted all kindergarten and cycle-one teachers, covering all the subjects: Arabic, English, French, math, science, geography, art, sport and religion. Thus, the total number of teachers was 34 . The program also involved all subject coordinators of the kindergarten and cycle one, so the total number of subject coordinators was seven. This particular study involved only 15 teachers $(\mathrm{N}=15)$ and those were the teachers of Grades 1-3.

\subsection{Research Instrument}

Two research instruments were developed and utilized for the collection of data pertaining to the research questions of this part of the study. The same instruments were administered to the same sample before and after the intervention so that comparisons can be made. School X administration approved the use of the instruments. Anonymity and confidentiality were highly respected. A four point Likert scale: $1=$ always done or available to $4=$ never done or available was used in all the instruments to rank the items. The instruments were scored by calculating the percentages of frequency.

\subsubsection{Classroom Data Collection Tool}

The intervention program was based on the active learning approach. All training sessions and workshops were focused on the active learning indicators that were adopted from the International Baccalaureate Organization (2008). Hence, the researchers developed a classroom observation tool including all the active learning indicators that were classified into three main fields: student, teacher and classroom environment. However, the researcher noticed that some indicators might not be observable throughout her class visits. The decision was made to address those indicators through two complimentary extension checklists. This helped maintain the objectivity of the measurement. Besides, some indicators were included in both the tool and the checklists for ensuring the triangulation of data. Table 1 shows the active learning indicators that were measured throughout the participant researcher classroom visits that preceded and followed the training.

Table 1: Classroom Observation Tool: Active Learning Indicators

\begin{tabular}{|l|}
\hline Student Field \\
\hline 1. Students ask questions orally. \\
\hline 2. Students ask questions that lead to investigations, ideas, suggestions and new questions. \\
\hline 3. Students associate new concepts to the ones they have already learned. \\
\hline 4. Students listen to each other attentively. \\
\hline 5. Students participate in the classroom. \\
\hline 6. Students explain their thoughts using the subject-related terms they have learned. \\
\hline 7. Students work in pairs and in groups. \\
\hline 8. Students express their thoughts in a variety of ways: diary, report, drawing or journals. \\
\hline 9. Students deduce conclusions using examples, trials and experiments. \\
\hline Teacher Field \\
\hline 10. Teacher provides materials and scientific thoughts suitable to the content being taught. \\
\hline 11. Teacher demonstrates and models the usage of the materials. \\
\hline 12. Teacher uses the subject-related terms convenient for teaching the content. \\
\hline 13. Teacher asks questions and offers suggestions. \\
\hline 14. Teacher asks open questions that inspire research, wondering and observation. \\
\hline 15. Teacher moves all around the classroom and is available for all students. \\
\hline 16. Teacher motivates students in a variety of ways. \\
\hline 17. Teacher listens attentively to the students' ideas. \\
\hline 18. Teacher supervises and guides students' discussions. \\
\hline 19. Teacher asks students to try new things. \\
\hline 20. Teacher provides feedback. \\
\hline 21. Teacher asks students to provide feedback. \\
\hline Classroom Environment Filed \\
\hline 22. Class is equipped and arranged for pair work and group work. \\
\hline 23. Materials are available for all students and are placed in easily attended places. \\
\hline 24. Students' work is displayed in the classroom. \\
\hline
\end{tabular}

As shown in Table 1, 24 indicators constituted the focus of the classroom observation tool. The tools allowed the researcher to measure the indicators in three separate fields. 


\subsubsection{Extension Checklist (1):}

Table 2 below includes the active learning indicators that were not measured inside the classroom. This checklist was administered to the participating teachers who ranked the items before and after they received the training.

Table 2: Extension Checklist (1): Active Learning Indicators

1. My students are self-confident; they take risks and ask questions.

2. My students are enthusiastic about researching and investigating.

3. My students utilize their time in conducting experiments and trials.

4. My students design the suitable testing to try their thoughts without expecting the answer

5. My students sort the information and the ideas and differentiate among them.

6. My students accept the knowledge they obtain from their researching and build upon it.

7. My students enjoy asking questions and consider it an essential part of their learning.

8. My students watch attentively, see the details and observe the changes.

9. My students link the new thoughts and ideas to the ones they have learned earlier.

10. My students are guided toward holding the responsibility and formulating conclusions.

11. My students feel safe and relaxed when expressing and sharing their thoughts.

12. My students support and affect each other.

\subsubsection{Extension Checklist (2):}

Table 3 below involves the indicators that were measured through investigating the lesson planning folders of the teacher participants. Two whole weekly plans of each teacher folder were examined twice, before and after the intervention.

Table 3:Extension Checklist (2): Active Learning Indicators

1. Different materials are used.

2. Learning strategies - including pair work and group work - are implemented.

3. Different learning styles - differentiated instruction - are considered.

4. Research-based tasks for students are assigned.

5. Activities for developing students' skills and their thinking methodology are planned.

6. Time for dialogues and class discussions is assigned.

\subsubsection{Teacher Leadership Survey:}

A survey was developed based on the extensive literature review of teacher leadership. The eight components that were mentioned in the conceptual framework (Figure 1) were addressed in this survey. The components were translated into practical items and classified into three fields: student, colleagues and self-development, and administration and supervision.

The survey was piloted. In addition, it was refereed by two experts in the field. Few amendments were made to the structure and wording of some items as a result of the pilot study and the experts' feedback. Table 4 below includes the survey items.

Table 4: Teacher Leadership Survey

Student Field

1. I involve my students in decision making.

2. I have my students hold the responsibility of their acts.

3. I encourage my students to experience errors.

4. I ask my students open questions paired with justification.

5. I explore my students' interests before planning the lesson.

6. I change the whole plan because of a student's question or wonder.

7. I utilize with each student a different strategy or technique that meets his/her needs.

8. I put my students in situations that require finding solutions to the problems.

9. My students perform most of the classroom tasks themselves, e.g. decoration - communication with others - setting rules etc

10. I specify more than half of the time to listen to my students.

11. I give my students the opportunity to share in setting the objectives and planning the activities with me.

12. I ask my students to evaluate my performance.

13. I ask my students to evaluate their peer's performance.

14. I listen to my students' opinions and suggestions.

15. I consider my students' suggestions the base of my planning.

16. I plan co-curricular activities on a wide level, e.g. competitions - exhibits etc.

17. I take my students on fieldtrips.

Colleagues and Self-Development Field

18. I conduct consistent research for new approaches in the education field.

19. I carry out an action research to handle a problem.

20. I share what happens in the class with my colleagues.

21. I invite my colleagues to attend a session in my class, observe my performance and provide feedback.

22. I ask my colleagues for support and advice. 


\subsection{The Intervention Program}

The intervention program was developed by an external team of professionals who worked closely with the school's senior and middle management teams. The purpose was to develop a program that closely matches teachers' and subject leaders' needs and hence leverage their capacities to improve their repertoire of practice within their classrooms in terms of leading student-centered classrooms. The intervention took place between October and May; at the rate of 1 training session monthly. It included workshops and training sessions, classroom observations, and coaching meetings. The participant researcher, served as a team assistant and attended all the aforementioned activities and documented it all. The intervention program included 7 full-day inhouse training sessions, entitled as follows: (1) Getting to know you workshops - Meet with teachers for a needs assessment discussion; (2) Moving Towards a Student-Centered Classroom; (3) Learning Centers and Invitations and Accountable Talk; (4) Deepening Accountable Talk and Managing Classroom Discourse and Interaction/ Questioning Strategies; (5) Adapting tasks- changing low level tasks to high level ones- and Emergent Literacy; (6) Visible Thinking and Documentation; and (7) Centers/ Assessment/ Discussion and Wrap-up. Besides, and as mentioned previously, there were classroom observations and coaching meetings with trainees between each two training sessions.

\subsection{Data Analysis}

Quanitative data derived from the instruments were treated statistically using Microsoft Office Excel. Frequency percentages were calculated per each indicator/item of the data collection instruments. Percentages of active learning indicators and teacher leadership items were presented in line graphs.

To better show the difference between results arrived at before and after the intervention, the researcherr created a progress scale that allowed her to locate the two basic notions of this part of the study: active learning and teacher leadership.

Locating the measured concept on the scale relied on the percentage of point (1) which meant always done or always available. The scale had five areas classified according to point (1) as follows:

Very weak: percentage of point (1) was $20 \%$ or lessWeak: percentage of point (1) was $40 \%$ or less Acceptable: percentage of point (1) was $60 \%$ or lessGood: percentage of point (1) was $80 \%$ or less Very good: percentage of point (1) was $100 \%$ or less

\section{Results}

As mentioned earlier, this part of the larger study aimed to explore the impact of the intervention program on reinforcing the student-centered classroom approach and on teacher leadership skills. To clearly show the impact, percentages of active learning indicators and those of teacher leadership items were calculated before and after the intervention. Graphical display of pre-intervention and post-intervention results was followed by discussion.

While discussing the pre-intervention results, all individual indicators/item were reported. However, the post-intervention discussions shed light only on indicators/items that were improved. When needed, percentages of Likert points (3) and (4) were grouped together in the narrative and referred to as rarely or never, just like the percentages of points (1) and (2) that were explained as always or sometimes.

\subsection{Research Question (1): How would an intervention program contribute to shifting classroom practice from being teacher-centered to become student-centered?}

The intervention program conducted in School X was mainly structured on active learning. Accordingly, the indicators of active learning were measured through the class observation tool, extension checklist (1) and extension checklist (2).

\subsubsection{Active Learning Indicators: Classroom Observation Tool}

4.1.1.1. Pre-Intervention

Figure 2 show the percentages of rankings arrived at through classroom observation tool when it was administered before the intervention. 


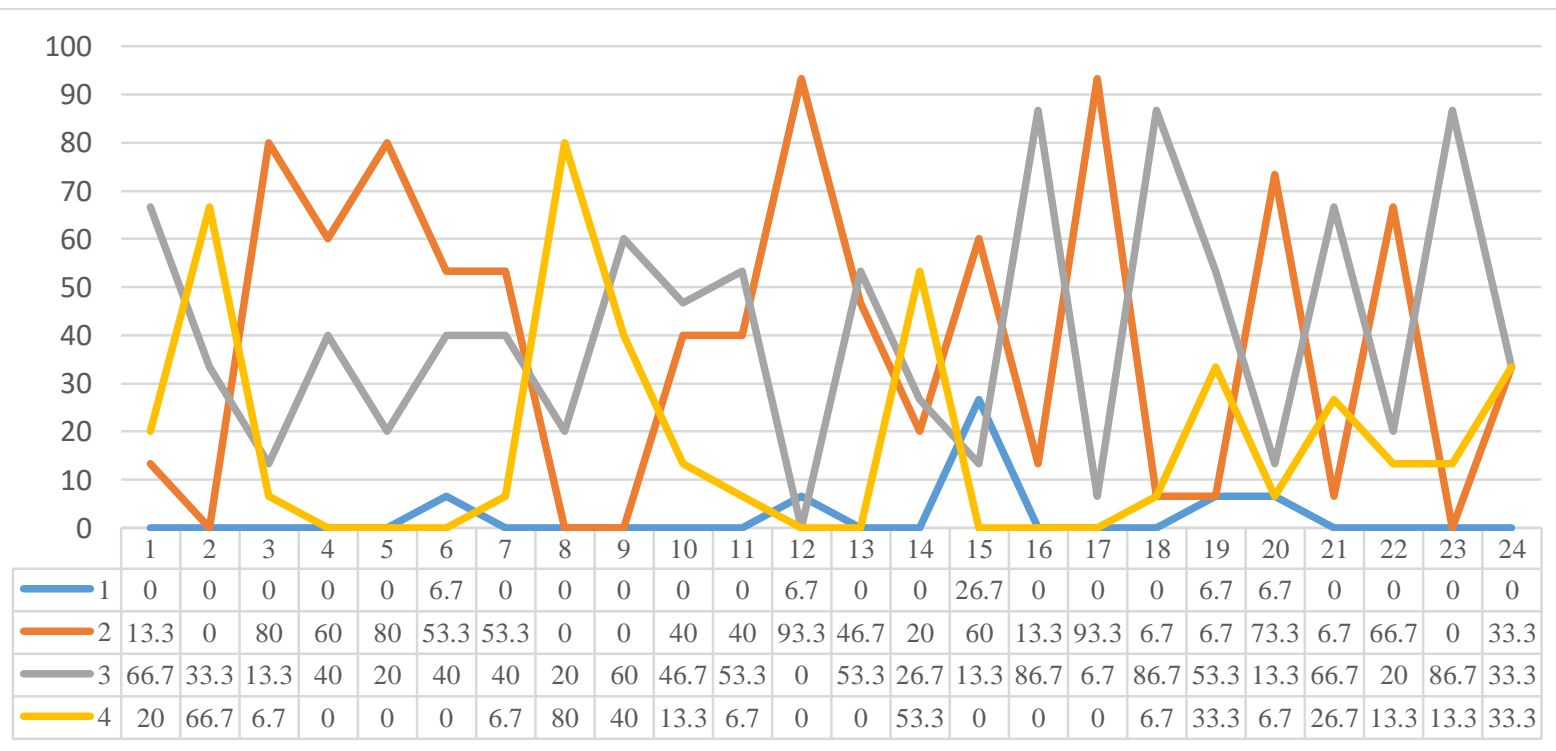

Figure 2. Percentages of active learning indicators (pre-intervention)

\section{Student Field}

Regarding oral questions asked by students, it was critical to find out that in $67 \%$ of the observed classes, students rarely asked oral questions and in $20 \%$ of them none of the students asked. Fitzsimmons (2011) declared that asking questions is crucial to the student learning and teachers have to consider the type of the questions asked. Chin (2001) considered that wonderment questions can facilitate knowledge construction by guiding the thinking process.

Hence, the tool, through the second indicator, sought to measure the type of questions asked. Actually in the majority of the attended classes, students never asked wonderment questions that could lead to investigations, ideas, suggestions and new questions; students rather asked factual and procedural questions and were satisfied by the answers they got. The lack of wonderment questions could deter students' stimulation to hypothesize, predict, seek and generate explanations (Chin, 2011).

In fact, Chin's finding is also related to indicator (9) which required students to deduce conclusions using examples, trials and experiments. $60 \%$ of the classes involved students who rarely did so, and in $40 \%$ of the classes, none of the students deduced conclusions in these ways. Craig \& Deretchin (2010) believed that experimentation and discovering are important aspects in the active learning approach.

Concerning the $3^{\text {rd }}$ indicator, data revealed that in the majority of the attended classes (80\%), students linked new concepts they were learning to the ones they've already learned while student rarely or never did so in the rest of the classes.
Percentages of the $4^{\text {th }}$ indicator showed that students in $60 \%$ of the classes sometimes listened to each other attentively and they rarely did in $40 \%$ of the classes. Participation, too, was not a regular practice of all students. Students in $80 \%$ of the classes sometimes participated and in the rest they rarely contributed to the discussion, asked questions or provided examples. This implied that students didn't have equal participation roles and opportunities. Czekanski \& Wolf (2013) stated that class participation is evidence of active learning. Additionally, when they participated, students in $40 \%$ of the classes rarely used subject-related terms to explain their thoughts.

During a large number of the attended sessions (40\%), group work and pair work strategies were rarely implement. Yet, in these classes lecturing was prevailing, and students acted as passive learners. Plus, all the observed classes had students who rarely or never expressed their thoughts through diaries, reports, journals or drawings.

\section{Teacher Field}

In shifting to the indicators that fell under teacher field in the classroom observation tool, percentages seemed not surprising in light of the previous results.

As per percentages of indicators (10) and (11), suitable materials and scientific methods were sometimes provided by teachers in $40 \%$ of the classes, yet they were rarely or never used in the rest of the classes. Among those who provided the suitable materials, a large number of teacher participants $(60 \%)$ rarely or never modeled the usage of the materials. The lack of modeling will ultimately diminish the benefit of the materials (Phipher, 2002). 
Through Figure 2, it was obviously shown that all the participating teachers used the subject - related terms for teaching the content. This reflected the teachers' deep knowledge of the subject they taught. However, it was not effectively reflected on the students who, in $40 \%$ of the classes, rarely used subject-related terms when expressing their thoughts.

Asking questions and offering suggestions were sometimes practiced by $47 \%$ of the teachers. However, $53 \%$ of them didn't. This result could justify the percentages obtained when measuring students' participation. Less questions and suggestions offered by the teachers imply less student participation (Czekanski \& Wolf, 2013).

Indicator (14) was related to the type of questions being asked by the teachers. The majority of participants didn't ask open questions that inspired research, wondering and observation. Only $20 \%$ of them sometimes asked such questions while the rest $(80 \%)$ rarely or never did. As such, having students who rarely or never asked wonderment questions was an expected result.

Similarly, it was shown through indicator (19) that the vast majority of teachers $(87 \%)$ rarely or never asked students to try new things. However, having students analyze, observe, discover and reflect could promote active learning (Segiovanni \& Starrat, 2007; Craig \& Deretchin, 2010).

Indicators (20) and (21) were interrelated. The collected data revealed that only $7 \%$ of the teachers always provided feedback, and the majority of them (73\%) sometimes did. However, the overwhelming majority $(93.4 \%)$ rarely or never asked students to provide feedback. Therefore, providing feedback was limited to the teacher. Noteworthy is to mention that when students provide feedback, they will eventually develop the ability to reflect on and assess their own performance (Craig \& Deretchin, 2010).

Data revealed that the vast majority of teachers $(87 \%)$ always or sometimes moved all around the classroom and were available for all the students. According to Fitzsimmons (2011) teachers who don't move around are those who adopt the teachercentered approach.

Indicator (16) showed that $87 \%$ of the participating teachers rarely motivated students in a variety of ways. Almost most of the observed teachers were motivating their students yet in the same way. This indicator fell under the differentiated instruction approach. In this context, Fenner et. Al., (2010) argued that if students don't feel appreciated for their differences in the way they are instructed and motivated, their achievement might be negatively influenced.

Concerning indicator (17), 93\% of the teachers sometimes listened attentively to students' ideas. It should be noted here that the ideas presented by students were neither controversial nor led to new investigations. Regarding indicator (18), 93\% of the participants rarely or never supervised and guided students' discussion. The current indicator was linked to the types of questions that were dominant, whether asked by the teachers or the students. As was shown in the student field, in the majority of the classes the discussion was limited and characterized by the close-ended questions and the short answers.

\section{Classroom Environment Field}

As for the classroom environment, the collected data revealed that the class equipment and arrangement for the pair work and the group work were rarely or never available in $33 \%$ of the classes. The current data confirmed the finding that $40 \%$ of the classes rarely included group work and pair work activities. In addition, the availability of materials to all students and the easy access to them were rarely or never existing in all the attended classes. This finding revealed that the usage of the materials was restricted to the teacher's decisions. Regarding students' work, it was rarely or never displayed in $66 \%$ of the classes. These classes included posters and pictures prepared by teachers.

\subsubsection{Post-Intervention}

Figure 3 below displays the percentages of classroom observation tool indicators after the intervention program. 


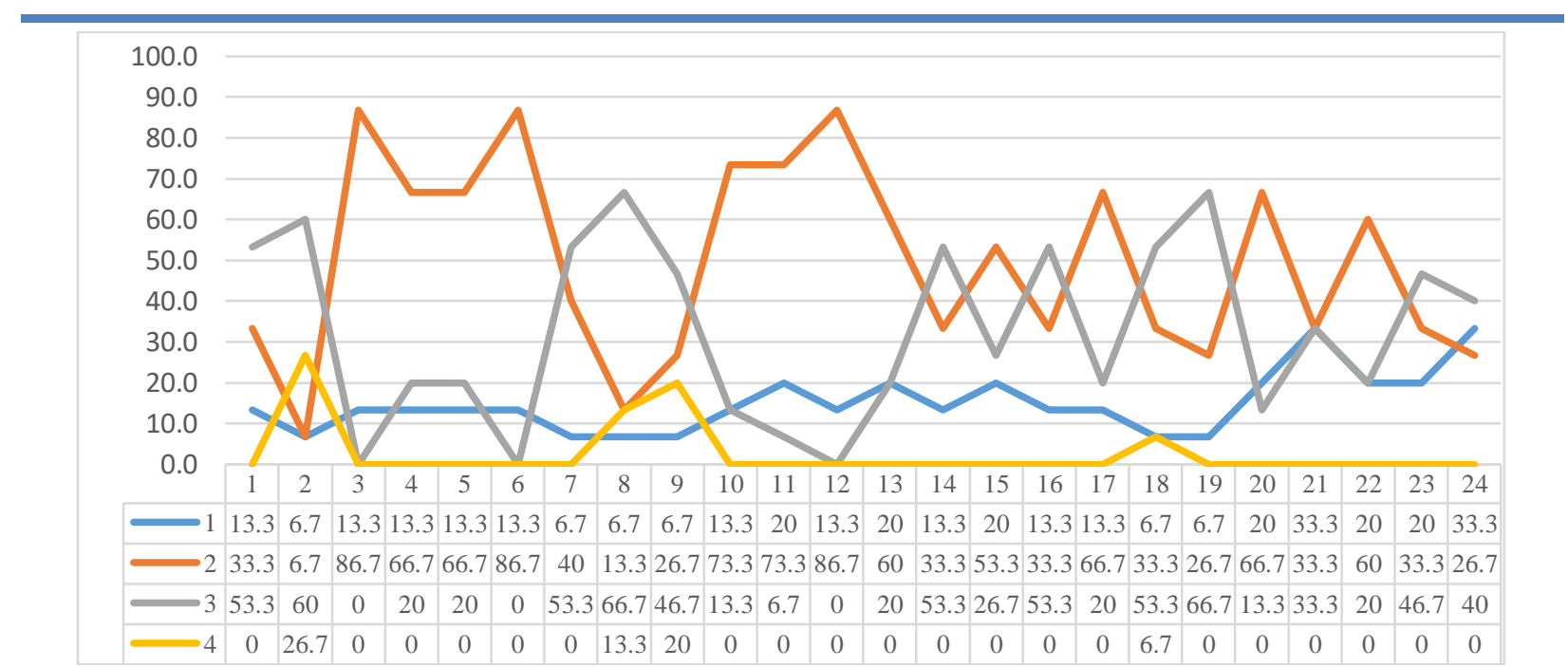

Figure 3. Percentages of active learning indicators (post-intervention)

Data derived from the classroom observation tool after the intervention revealed that some indicators were ranked higher while others recorded almost the same rankings during the two stages.

Concerning the student field, data collected after the intervention showed slight progress in some indicators. For instance, the percentage of the classes where students always or sometimes asked questions evolved from $13 \%$ in the pre-intervention stage to $46 \%$ in the current stage. However, the factual procedural questions were still dominant whereby in $87 \%$ of the classes, students rarely or never asked wonderment questions.

Students' participation in the classes recorded slight improvement. Additionally, pair work and group work strategies became more frequent in some classes after the intervention.

The percentage of the classes where students deduced conclusions using trials and experiments also increased; however, it was still low as only in $33 \%$ of the observed classes, students always or sometimes did so. Although the occurrence of the current indicator was still weak, the progress that happened was noteworthy given that in the pre-intervention stage, all students rarely or never deduced conclusions.

As for teachers' practices, some indicators recorded slight progress while others showed no change. For instance, the percentage of teachers who provided materials and scientific thoughts suitable to the content has changed. In the post-intervention stage, $87 \%$ of the teachers always or sometimes provided such things while the percentage of this indicator in the pre-intervention stage was $40 \%$.
In addition, questions and suggestions offered by the teachers have improved. $80 \%$ of the teacher participants always or sometimes asked questions and offered suggestions whereas only $47 \%$ of them did so in the pre-intervention stage. The current indicator was related to indicators (1) and (2) in the student field. After the intervention, all the three indicators improved to some extent. This finding aligned with Fitzsimmons's (2011) suggestion that considered asking questions as an important strategy that should be modeled and reinforced by the teacher.

The percentage that represented teachers who always motivated their students in a variety of ways has increased. In addition, teachers became more effective in guiding students' discussions.

Regarding indicator (12), the percentage that represented teachers who always or sometimes asked students to provide feedback has evolved from $7 \%$ to $67 \%$ after the intervention. This implied that students' roles became more active when compared to their roles before the intervention.

Concerning the classroom environment field, little changes were noticed. Classes became more equipped for pair work and group work strategies; more materials were available in the classrooms for students; and additional display of students' work was seen on the bulletin boards. However, the progress was still limited and insufficient. For instance, $20 \%$ of the classes were still rarely equipped and arranged for pair work and group work; $47 \%$ of the classes rarely included easily accessible materials for students and in $40 \%$ of the classes, students' work was rarely displayed. 


\subsubsection{Active Learning Indicators: Extension Checklist (1) \\ Figures 4 below shows the percentages of data 4.1.2.1. Pre-Intervention derived from extension checklist (1) that was administered prior to the intervention.}

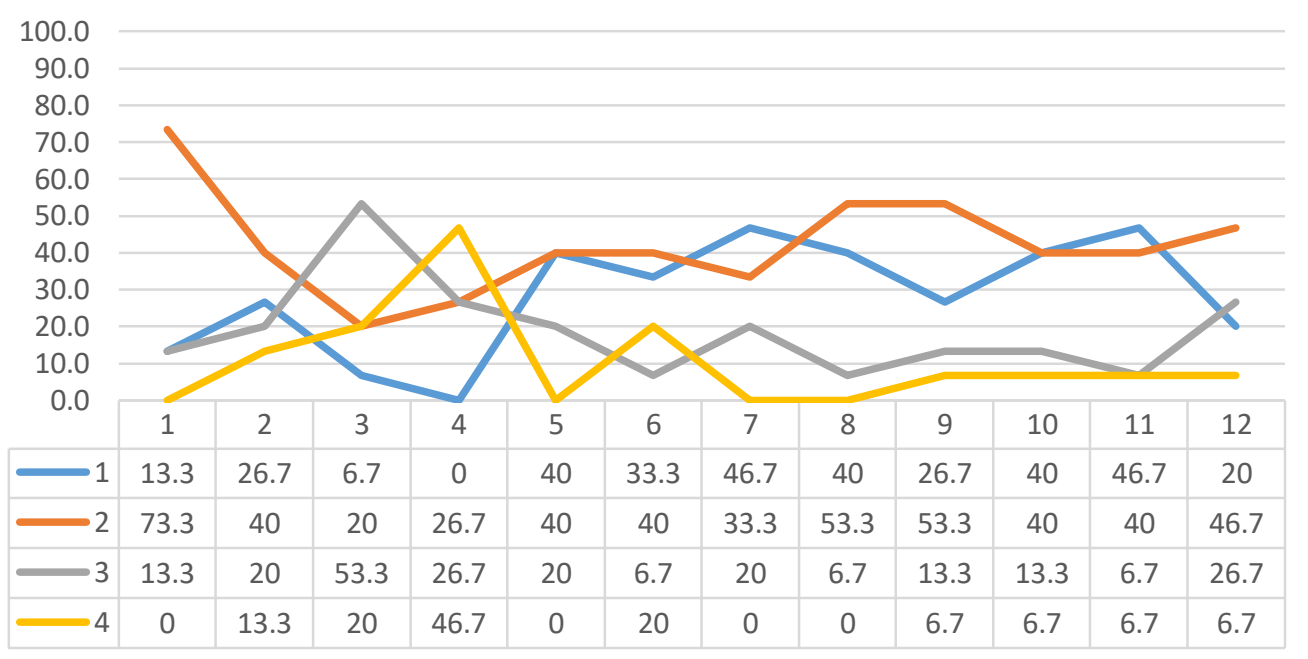

Figure 4. Percentages of checklist (1) indicators (pre-intervention)

The majority of teachers $(87 \%)$ believed that their students were always or sometimes self-confident and able to take risks and ask questions. $67 \%$ of the teachers believed that their students were always or sometimes enthusiastic about researching and investigating. In addition, the majority of teachers ranked indicators (6), (7) and (8) high. $73 \%$ of the teachers believed their students always or sometimes accepted the knowledge they obtained from their researching and built upon it. $80 \%$ of them reported that their students always or sometimes enjoyed asking questions and considered it an essential part of their learning. The overwhelming majority (93\%) admitted that students always or sometimes watched attentively, noticed the details and observed the changes.

On the contrary, by referring to the data derived from classroom observation tool, it was noticed that the vast majority of the students were rarely or never engaged in learning through research, experimentation and discussion. This contradiction implied that some teachers had opinions and thoughts that didn't align with the actual performance of students. Concerning indicator (9), the obtained results agreed with those of indicator (3) of the classroom observation tool where students associated new concepts to the ones they had already learned.
Regarding indicator (11), the majority of teachers $(87 \%)$ believed that their students always or sometimes felt safe and relaxed when expressing and sharing their thoughts; however, during the attended sessions, it was noticed that the vast majority of students never expressed their thoughts in a variety of ways. The interpretation of the current case revealed that the students were not provided by sufficient opportunities to express their thoughts.

Concerning indicator (12), $67 \%$ of the teachers believed that their students always or sometimes supported and affected each other. This result was related to the previous indicators pertaining to pair work and group work. In $53 \%$ of the classes, students sometimes worked in groups, and $67 \%$ of the classes were sometimes arranged and equipped for group work and pair work. The results of the three indicators were compatible. This finding aligned with the conclusion provided by Williams who stated that within the group work, students support and affect each other positively as they exchange knowledge and experience (Williams, 2011).

\subsubsection{Post-Intervention}

Figure 5 displays the percentages of checklist (1) indicators after the intervention. 
Rejunevating Teacher Leadership Capacity through an in-service Training Program Focusing on Active Learning: A Case Study

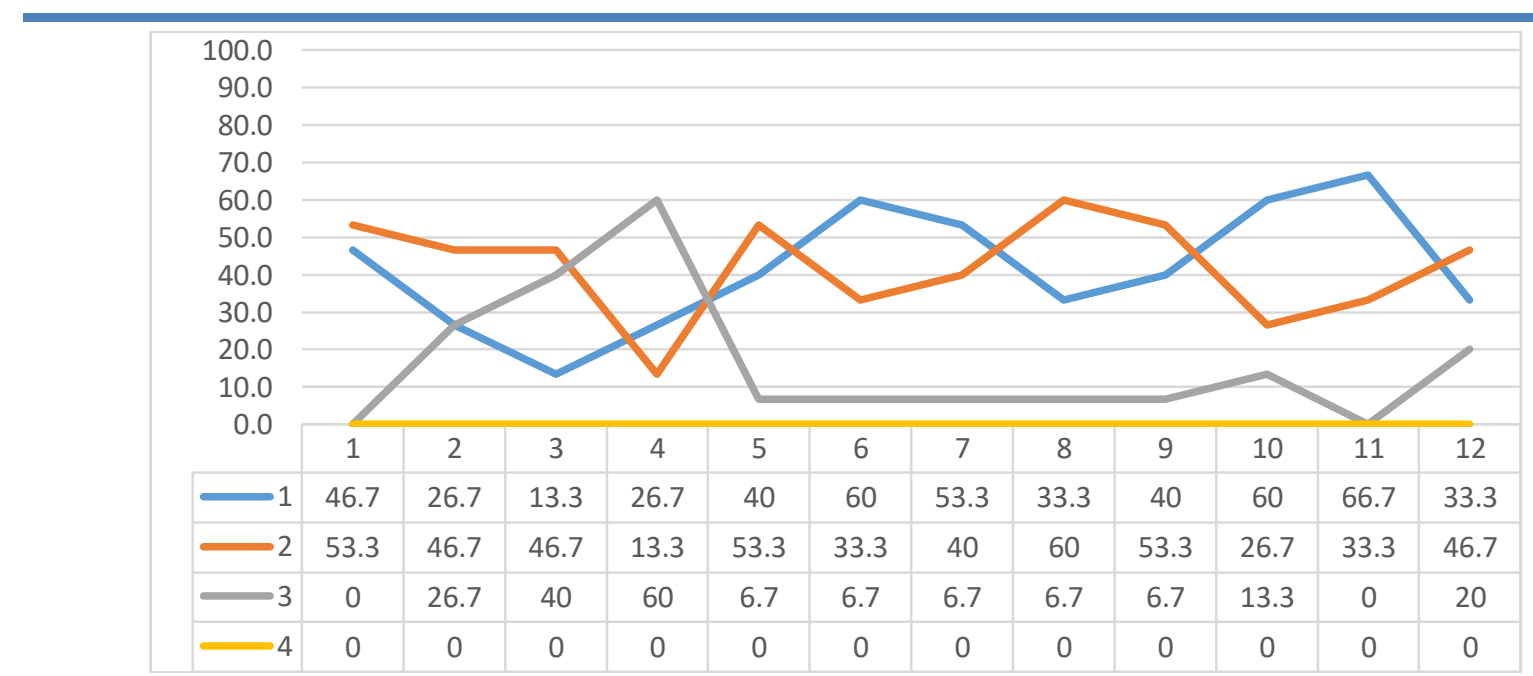

Figure 5. Percentages of checklist (1) indicators (post-intervention)

Data collected via the extension checklist (1) after the intervention revealed that teachers seemed to have a more positive attitude towards their students' potentials. For instance, the percentage of teachers who stated that their students rarely or never utilized their time in conducting experiments and trials declined from $73 \%$ to $40 \%$.

All the teachers in the post-intervention stage believed that their students always or sometimes felt safe and relaxed when expressing and sharing their thoughts. In addition, teachers became more willing to guide their students towards holding the responsibility and formulating conclusions.
It is important to note at this point that the researcher had noticed a clear contradiction between what some teachers stated and what they actually did in their classes. This implied that the teachers tried to show the perfect image although it was not reflecting their real practices. Teachers at school $\mathrm{X}$ always had the worry of being assessed. Thus, they always used to justify their practices and give excuses and reasons even when not being asked to.

\subsubsection{Active Learning Indicators: Extension} checklist (2)

4.1.3.1. Pre-Intervention

Percentages of extension checklist list (2) indicators that were obtained before the intervention are shown in Figure 6 below.

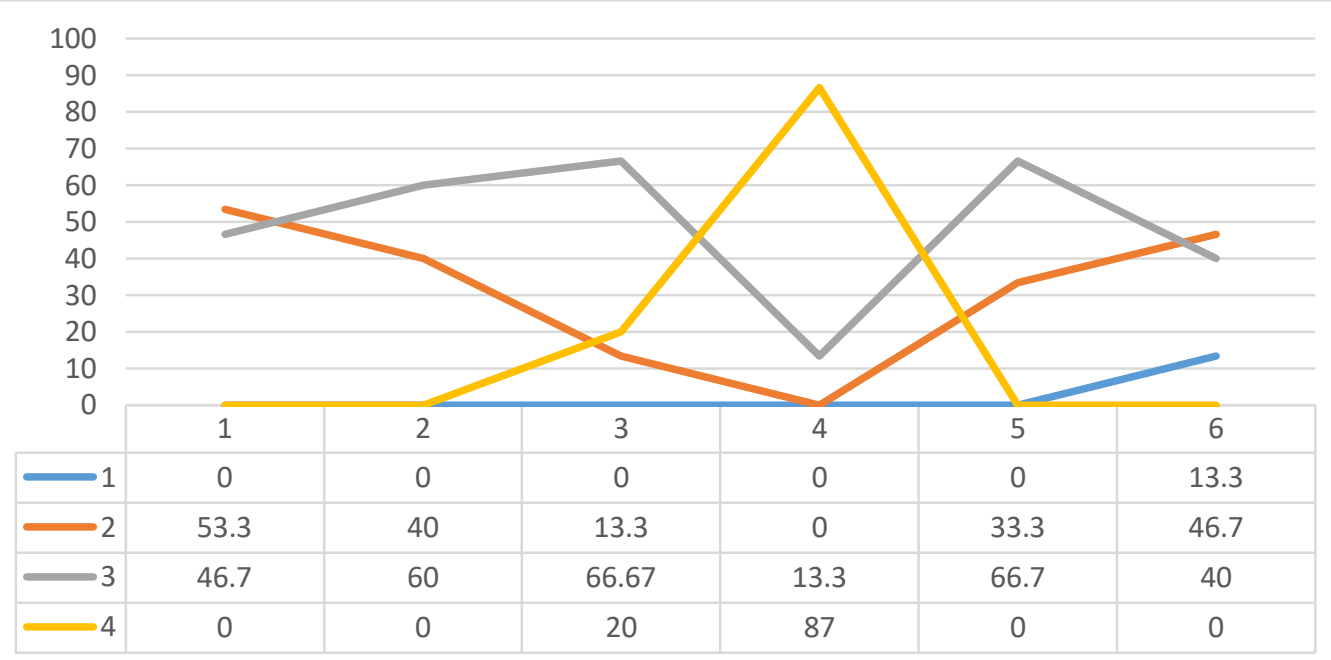

Figure 6. Percentages of checklist (2) indicators (pre-intervention)

In the vast majority of the lesson planning folders (87\%), considering different learning styles was rarely or never available, yet the usage of the same learning style was prevailing. This finding was confirmed by referring to indicators (1) and (2). Different materials were rarely available in $47 \%$ of the lesson plans and the variety of strategies was rarely seen in $60 \%$ of them. Actually, the results 
represented another proof for the dearth of the differentiated instruction that was concluded earlier. Fenner et al. (2010) concluded that using different strategies and a variety of materials contribute to differentiation that allows students to grow academically.

The result that was obtained through the previous instruments concerning students' engagement in research was confirmed by indicator (4) whereby all the lesson plans rarely or never included research based tasks for students.

According to the related literature, developing students' thinking skills is an essential aspect of active learning. However, this indicator was rarely or never available in all the folders.

Data indicated that in $60 \%$ of the folders, specifying time for dialogues and class discussion was always or sometimes available. Yet, the rest $(40 \%)$ of the teachers rarely specified time for this purpose.

\subsubsection{Post-Intervention}

Figure 7 below presents the percentages of extension checklist (2) indicators after the intervention.

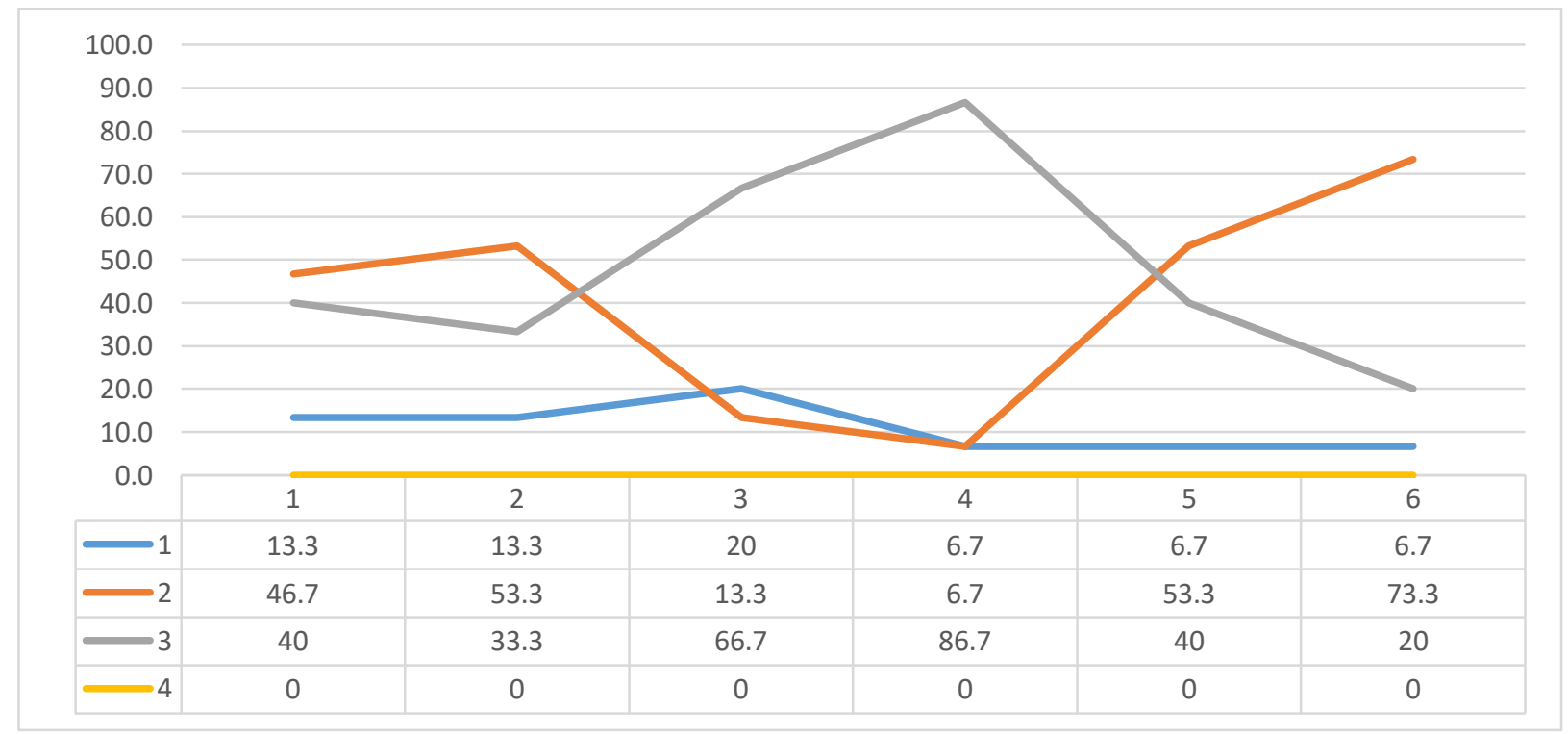

Figure 7. Percentages of checklist (2) indicators (post-intervention)

Data derived through inspecting the lesson planning folders after the intervention program showed that slight changes to the lesson plans were made. For instance, assigning research-based tasks for students was rarely or never available in all the lesson planning folders before the intervention. Yet, it became always or sometimes available in $13 \%$ of the folders after the intervention.

Different learning styles got higher rankings in the current stage as being compared to the previous stage. In addition, the percentage that represented varying strategies and including pair work and group work decreased from being rarely available in $60 \%$ of the folders in the pre-intervention stage to become rarely available in $33 \%$ of the folders in the postintervention stage.

\subsubsection{Active Learning Indicators on the Progress Scale}

This section shows the progress achieved by the intervention program in terms of active learning indicators. The frequency percentage of point (1) in the classroom observation tool and the two extension checklist before the intervention was $9.7 \%$. 
Rejunevating Teacher Leadership Capacity through an in-service Training Program Focusing on Active Learning: A Case Study

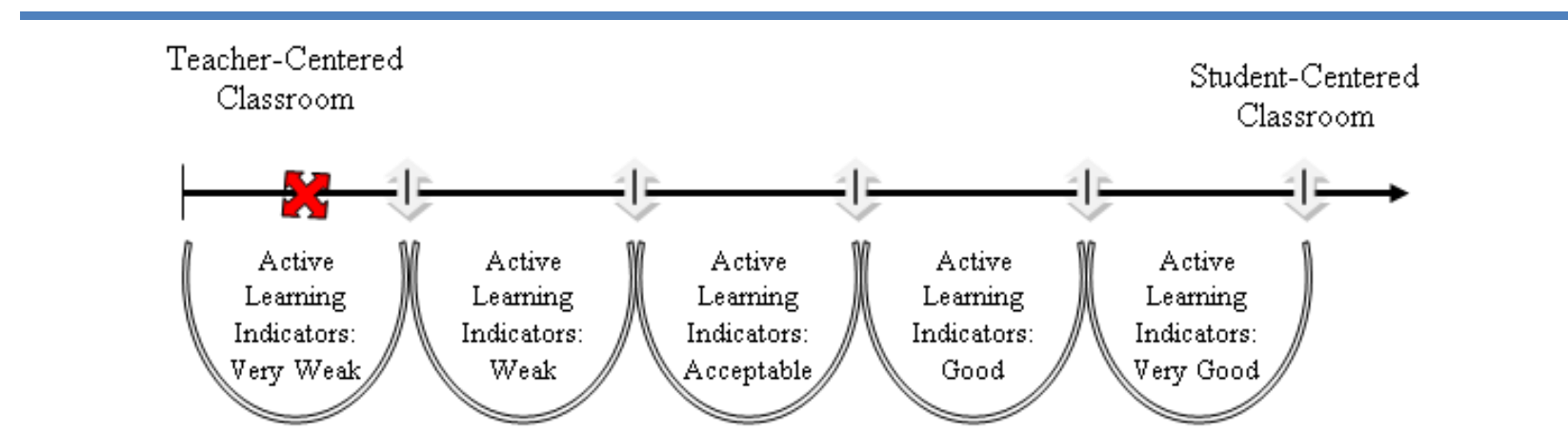

Figure 8. Active learning indicators on the progress scale before the intervention

As shown in Figure 8, the concept of active learning indicators before the intervention was located in the very weak area since the percentage of point (1) was below $20 \%$. This implied that classrooms were teacher-centered.

After the intervention, data revealed that the frequency percentage of point (1) was raised to become $22.1 \%$.

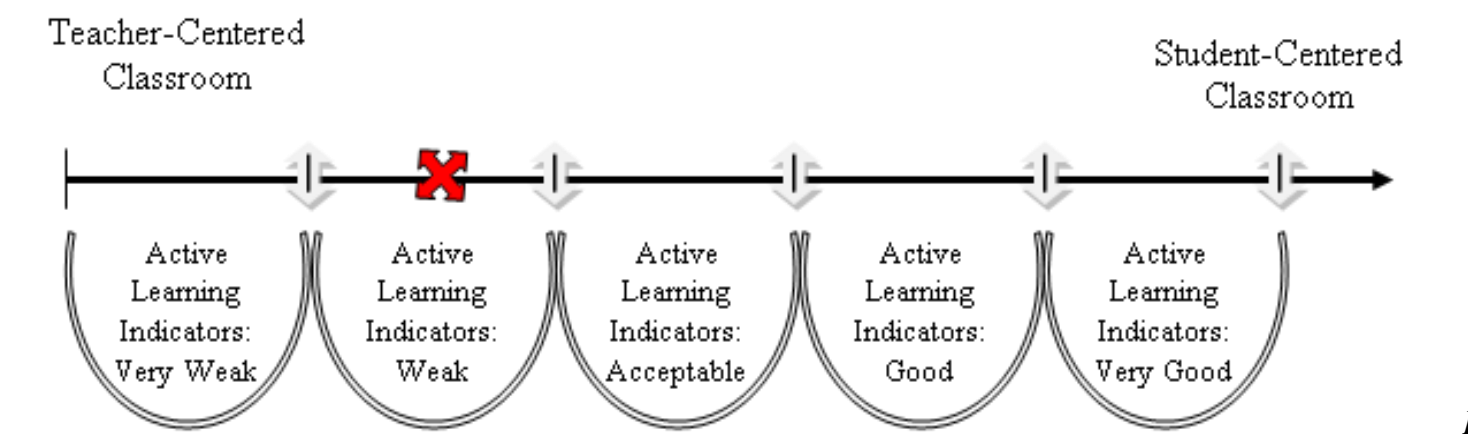

Active learning indicators on the progress scale after the intervention

Figure 9.

Figure 9 clearly shows the shift that happened after the intervention. The notion of active learning indicators was located in the weak area since the frequency percentage of point (1) was promoted to fall between $21 \%$ and $40 \%$. As shown through the scale, after the intervention classrooms were still closer to being teacher-centered.

4.2. Research Question (2): How do the leadership practices of teachers evolve during the course of the intervention?
Investigating the impact of the intervention on teacher leadership skills was measured through administering teacher leadership survey to the participating teachers before and after the intervention.

\subsubsection{Pre-Intervention}

Figure 10 shows the percentages obtained through administering the teacher leadership survey before the intervention.

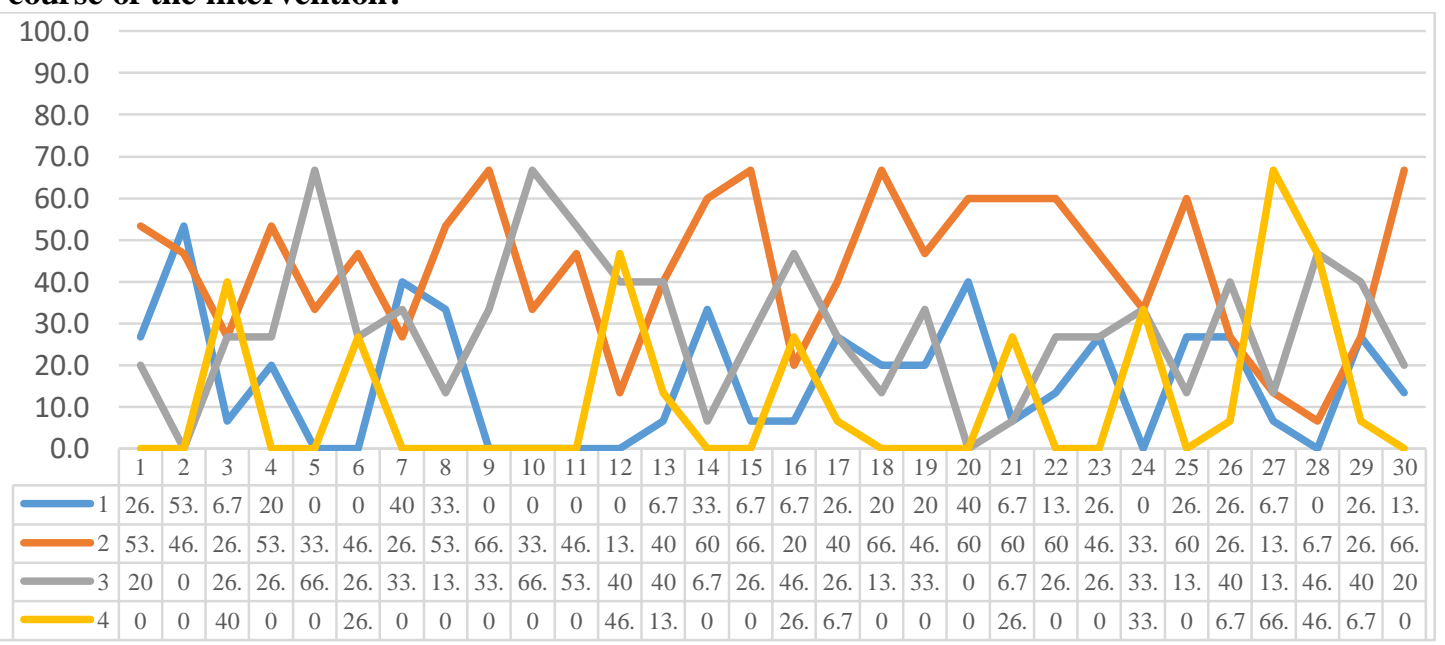

Figure 10. Percentages of teacher leadership items (pre-intervention) 


\section{Student Field}

The student field in the teacher leadership survey contains several related items that will be interpreted in the same context. The majority of teachers $(80 \%)$ stated that they always or sometimes involved students in decision making, and the rest rarely did. More than half of the teachers (53\%) stated that they rarely had their students share in setting objectives and planning activities and $67 \%$ of the participants admitted that their students sometimes performed tasks like decoration, communication with others and setting the classroom rules. Based on the foregoing, it was concluded that students shared in decisions and things related to general classroom issues, yet setting learning objectives and planning activities were accomplished by the teacher.

$67 \%$ of the teachers stated that they specified more than half of the time to listen to their students. The obtained result was parallel to the previous one where 93\% of the teachers stated that they always or sometimes listened to their students' opinions and suggestions. In the same context, $73 \%$ of the teacher participants always or sometimes considered students' suggestions the base of their planning.

Concerning items (5) and (6), the majority of the participating teachers $(67 \%)$ stated that they rarely explored the students' interests before planning the lesson and $53 \%$ of them stated that they rarely or never changed the whole plan because of a student's question or wonder. The current results reflected the teachers' dedication to the plan, and they contradicted the results obtained earlier whereby the majority of teachers stated that they considered students' suggestions as the base of their planning. Students' questions reflect their interests that should be taken into consideration as according to Sergiovanni \& Starrat (2007), the teacher leader is characterized by the flexibility in which he/she has the willing to throw away a lesson plan as a respond to students' questions.

All the teachers stated that they always or sometimes had their students hold the responsibility of their acts. $67 \%$ of the participants stated that they rarely or never encouraged students to experience errors.

$53 \%$ of the teachers reported that they rarely or never asked the students to evaluate their peers' performance, and $47 \%$ of them stated that they always or sometimes did. Conversely, during the classroom observation, it was noticed that the vast majority of the teachers $(93 \%)$ rarely or never asked students to provide feedback.

The majority of teachers (87\%) stated that they rarely or never asked their students to evaluate their performance. The current finding didn't align with the finding of Sergiovanni \& Starrat (2007) who believed that teacher leaders are open to the feedback and trust their students' potentials.

In the same context, items (4) and (8) were related for they measured the extent to which teachers put their students in situations that required finding solutions to problems and asking open questions paired with justification. $73 \%$ of the teachers stated that they always or sometimes asked open questions that required justification and $86 \%$ of the teachers stated that they always or sometimes exposed their students to problems that entailed solutions. These results contradicted the actual performance observed in the classrooms.

Concerning items (16) and (17), only $27 \%$ of the teachers admitted that they always or sometimes planned co-curricular activities on a wide level e.g. competitions and exhibitions. In addition, $67 \%$ of the teachers always or sometimes took students on field trips. In fact, these two items were decided based on the curriculum and the yearly plans.

As for item (7), $67 \%$ of the teachers stated that they always or sometimes utilized with each student a different strategy or technique that meets his/her needs, and only $33 \%$ of them stated that they rarely did. This result strongly contradicted the finding that was obtained earlier. The related literature ensured the significance of differentiation in the classroom (Sergiovanni \& Starrat, 2007; Fenner et al., 2010).

\section{Colleagues and Self-Development Field}

$87 \%$ of the teachers stated that they always or sometimes conducted a consistent research for new approaches in the education field. Additionally, 67\% of them stated that they always or sometimes carried out action research to handle problems. At this point, it's important to refer to the finding of Lumpkin et al. (2014) who stated that teacher leaders use data and evidence in making decisions and solving problems. Items (20), (21) and (22) referred to the collaboration with colleagues that is enhanced by literature as the most powerful tool of teacher leadership (Donaldson, 2006; Sergiovanni \& Starrat, 2007; Lumpkin et al., 2014). Data showed that all the teachers always or sometimes shared what happened in the class with their colleagues, and $67 \%$ always or sometimes invited their colleagues to attend a session in their class, observe their performance and provide feedback. In addition, $73 \%$ of the teachers stated that they always or sometimes asked their colleagues for support and advice. During her class observations, the researcher noticed that some teachers were complaining about her unscheduled visit although they were acknowledged by the director. 
Concerning item (24), 66\% of the teachers stated that they rarely or never shared their experiences with teachers in other schools. This result implied that the majority of teachers didn't show openness to other schools. $74 \%$ of the participants admitted that they always or sometimes experienced methods and strategies that were not specified by the coordinator.

The concept of self-evaluation was measured through item (25). $87 \%$ of the teachers stated that they always or sometimes evaluated their performance. This finding aligned with item (1) whereby the same percentage of teachers (87\%) always or sometimes conducted research in the education field. Based on the foregoing, it could be argued that teachers who evaluated themselves were those who conducted research in the education field. Moreover, item (26) showed that $47 \%$ of the teachers rarely or never attended workshops and training courses. According to the related literature, teacher leaders should commit to continuous professional development activity and seek learning in different ways (Lumpkin et al., 2014).

Regarding the development of their own portfolio, the vast majority of teachers $(80 \%)$ rarely or never developed their portfolio. It is important at this point to note that the majority of teachers hadn't heard about portfolios before.

\section{Administration and supervision field}

The vast majority of teachers $(94 \%)$ reported that they rarely or never shared in making decisions on the school-wide level. This result could be widely discussed when linking it to the teacher leadership. Empowering teachers as decision makers has positive effects on the school and the students (Sergiovanni \& Starrat, 2007; Xu \& Patmor, 2012; Ghamrawi, 2013). The current discussion could clarify the reason behind rarely engaging students in decision making.

Concerning items (29) and (30), 47\% of the teachers stated that they rarely or never shared in decision making on the department-wide level, and $20 \%$ of them considered that their suggestions and opinions during the class meetings were rarely taken into consideration.

\subsubsection{Post-Intervention}

Teacher participants ranked the items of teacher leadership survey after the intervention. Figure 11 below shows the percentages.

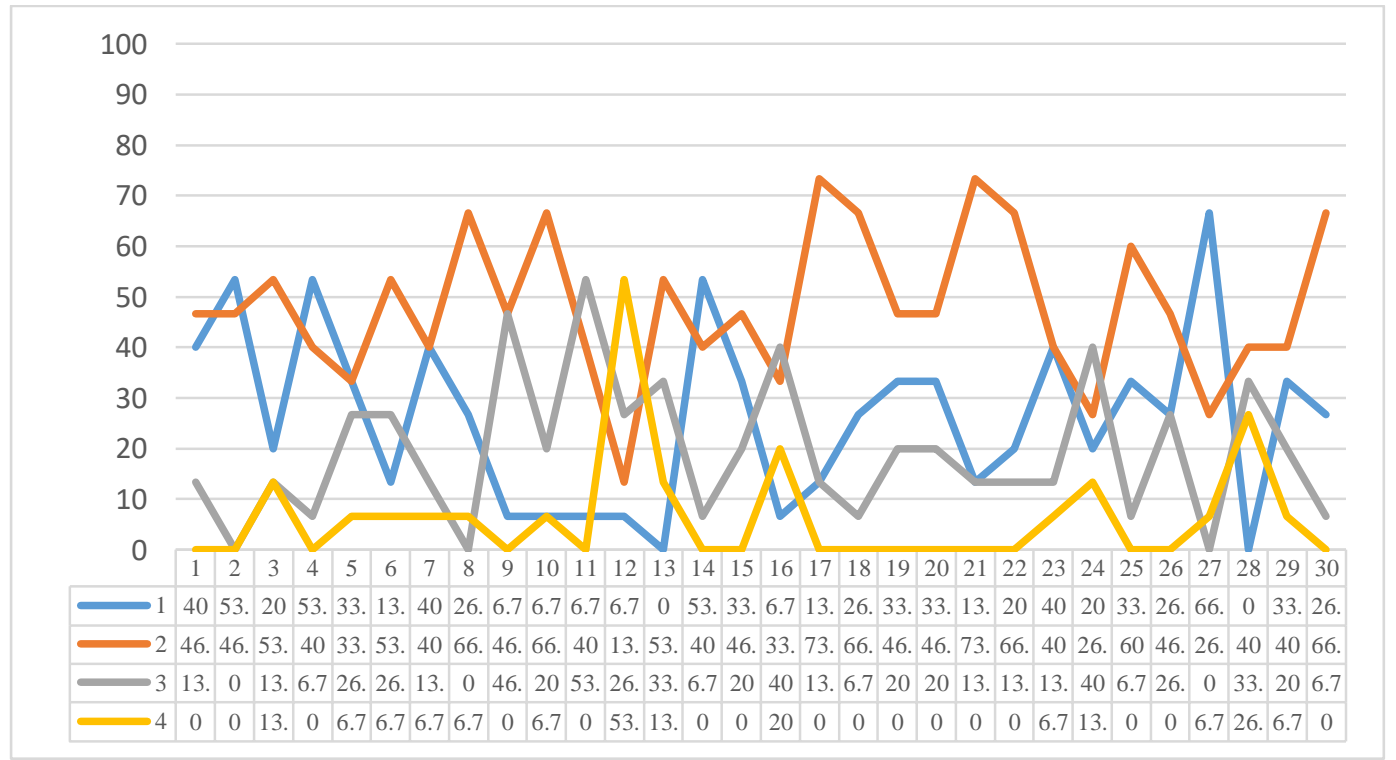

Figure 11. Percentages of teacher leadership items (post-intervention)

Data arrived at through administering the teacher leadership questionnaire to participants after the intervention revealed that some practices were evolved.

The percentage of teachers who rarely or never encouraged their students to experience errors decreased from $67 \%$ to $13 \%$ after the intervention. Similarly, the percentage that represented teachers who asked open questions also improved. The finding confirmed the previously-mentioned progress in the class discussion. However, this progress was not noticed in all the classes.

According to the teachers' responses, students seemed to have more active roles in performing tasks, giving suggestions and finding solutions to problems. However, other items didn't record any change. 
As for colleagues and self-development field, the changes were very limited. The most noticeable change was related to portfolio. The percentage that represented this item raised to reach $94 \%$ after the intervention as teachers were required to develop their professional portfolio.

The percentage that represented teachers who always or sometimes invited their colleagues to attend their classes has slightly evolved. Yet, it was still noticed that $13 \%$ of them rarely did so.

Changes concerning the items of the administration and supervision field were slight, too. The percentage that represented teachers who rarely or never shared

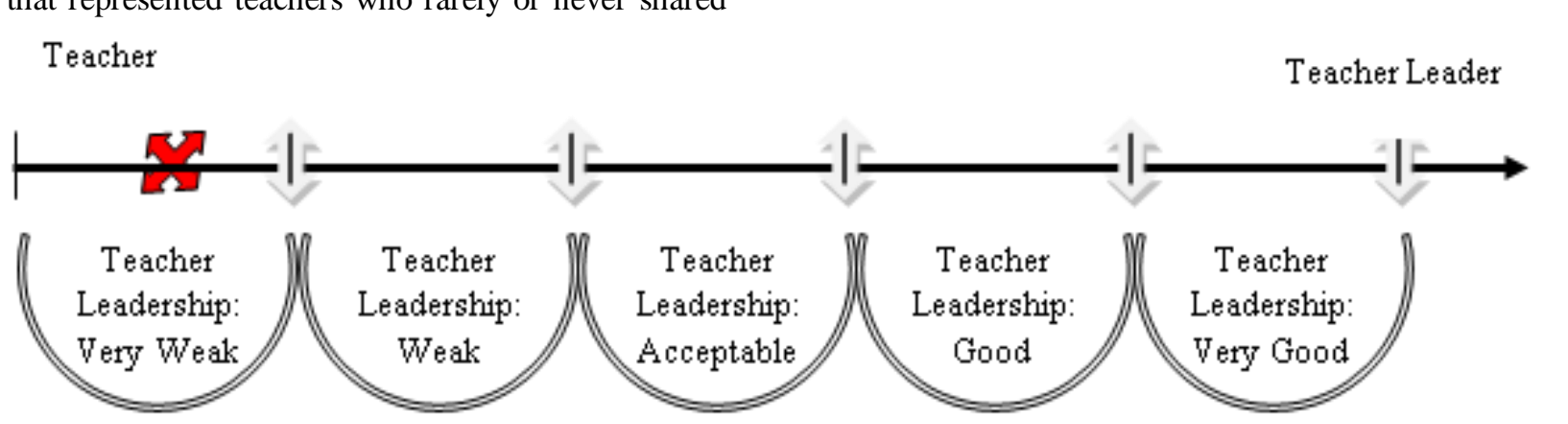

Figure 12. Teacher leadership on the progress scale before the intervention

Given that the percentage was below $20 \%$, the concept of teacher leadership was located in the very weak area prior to the intervention. Hence, teacher participants did not possess teacher leadership skills. in decision making decreased after the intervention. Yet, a significant number of teachers $(57 \%)$ stated that they rarely or never shared in decision making on the school-wide level, and $27 \%$ of them rarely or never shared in decision making on the departmentwide level. The findings implied that leadership at school $\mathrm{X}$ was not quite shared with the teachers.

\subsection{Teacher Leadership on the Progress Scale}

The progress scales in Figures 12 and 13 below show the impact of the intervention program on teacher leadership practices. The frequency percentage of point (1) in the teacher leadership survey was $16.2 \%$ before the intervention.

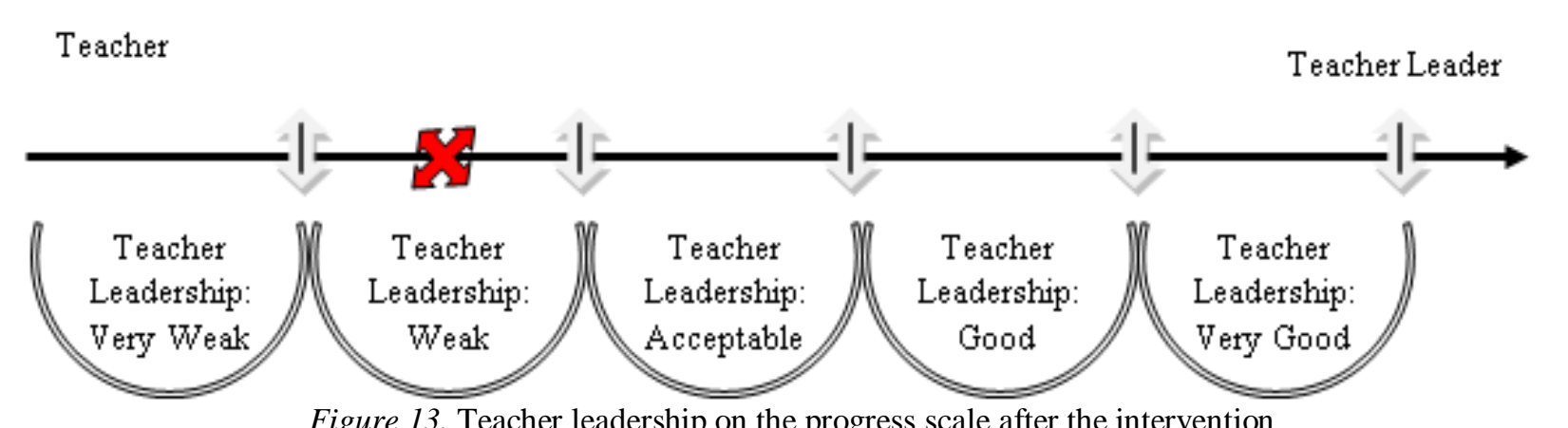

Figure 13 demonstrates the progress that was achieved as a result of the intervention. Teacher leadership aspect was located in the weak area. The slight progress did not turn teacher participants into teacher leaders.

\section{Summary and Conclusion}

Data indicated that the intervention program had a slight impact on transforming teacher-centered classrooms into student-centered environments. It contributed to shifting the active learning indicators from the status of very weak to that of weak. Concerning the impact of the intervention program on the teacher leadership practices, it was also slight in which teacher leadership was moved from the very weak area into the weak area. However, the progress
After teachers were trained on implementing the active learning approach, the frequency percentage of point (1) in the survey was lifted to reach $26.2 \%$. 
centered classroom. In other words, this study confirmed that student-centered classroom approach could be hardly adopted by a teacher with weak leadership potentials.

The intervention program made considerable yet slight improvements to the classroom styles and to teacher leadership practices. Students in the studentcentered classroom are independent learners who learn through experimentation, discovery, questioning and participation (Ahmed, 2013; Craig \& Deretchin, 2010). Sergiovanni \& Starrat (2007) believed that only teachers with great leadership potentials can run a student-centered classroom. Ghamrawi (2013) concluded that subject coordinators who own leadership potentials can empower and develop teacher leaders. By combining the above findings, it could be told that the reason behind having slight improvement becomes justified. Teacher leadership potentials at school $X$ were insufficient and not reinforced by the school.

Additionally, approaching the problem of teachercentered classrooms in a backward form resulted in slight progress since leadership according to Donaldson (2006) combines beliefs, thinking philosophy, and practice. Hence, evolving it indirectly could be hindered by it inflexibility.

\section{Limitations of the Study}

Two research questions were addressed in this study which is part of a larger study. Quantitative data were collected and percentages were calculated to show the progress. Qualitative data would have enriched the study and provided more in-depth insights. Additionally, inferential statistics would have revealed important relationships between variables and hence contributed to further investigations.

\section{Recommendations}

This study sheds light on two important complementary concepts that have the power to develop students' skills and hence prepare them to handle real-life challenges. Addressing teachers' weak leadership in a backward direction has resulted in obtaining little progress. Therefore, aligning with the related literature, this study has shown that developing teacher leadership is a prerequisite for creating student-centered environments.

Hence, it is important for policy-makers, stakeholders and school administrations to recognize the significance of developing the leadership potentials of teachers. Professional development activities that aim at changing the learning environment must first empower teachers and shift their perceptions of their roles in the classroom. This issue entails schools to reconsider their prevailing leadership style.

\section{References}

1. Ahmed, K., A. (2013). Teacher-Centered Versus LearnerCentered Teaching Style. The Journal of Global Business Management, 9(1), 22-34. Retrieved November 30, 2015 from http://http://www.teach.org

2. Attard, A., Ioio, E., Geven, K., \& Santa, R. (2014). Studentcentered learning. An insight into theory and practice. Bucharest: Education International.

3. Berek, D. (2013). Active learning. Salem Press Encyclopedia [serial online]. September 2013; Available from: Research Starters, Ipswich, MA

4. Berry, B., Daughtrey, A., \& Wieder, A. (2010). Teacher Leadership: Leading the Way to Effective Teaching and Learning. Center for Teaching Quality. Retrieved March 10 , 2015 from http://www.teach.org

5. Bonwell, C. C., \& Eison, J. A. (1991). Active Learning. Creating Excitement in the Classroom. 1991 ASHE-ERIC Higher Education Reports. ERIC Clearinghouse on Higher Education, The George Washington University, One Dupont Circle, Suite 630, Washington, DC 20036-1183.

6. Chin, C. (2001). Student-Generated Questions: What They Tell Us about Students' Thinking. Retrieved from the Eric database.

7. Colthorpe, K., Chen, X., \& Zimbardi, K. (2014). Peer Feedback Enhances a" Journal Club" for Undergraduate Science Students That Develops Oral Communication and Critical Evaluation Skills. Journal of Learning Design, 7(2), 105-119.

8. Craig, J., C., \&Deretchin, F., L. (2010). Cultivating Curious and Creative Minds. United States of America: Rowman and Littlefield.

9. Czekanski, K. E., \& Wolf, Z. R. (2013). Encouraging and Evaluating Class Participation. Journal of University Teaching and Learning Practice, 10(1), 7.

10. Donaldson, G. (2006). Cultivating Leadership in Schools. New York and London: Teacher College Press.

11. Fenner, D., Mansour, K., S., \& Sydor, N. (2010). The Effects of Differentiation and Motivation.on Students Performance. Master Degree in Arts in Teaching and Leadership, Saint Xavier University, Chicago, Illinois. Retrieved from the Eric database.

12. Fink, L. D. (2013). Creating significant learning experiences: An integrated approach to designing college courses. John Wiley \& Sons.

13. Fitzsimmons, M. (2011). Students Asking Questions in the Middle School Mathematics Classroom. Online Submission. Retrieved from the Eric database.

14. Fullan, M., \& Langworthy, M. (2013). Towards a new end: New pedagogies for deep learning. Retrieved March 18, 2015 from https://michaelfullan.ca/wpcontent/uploads/2013/08/New-Pedagogies-for-DeepLearning-An-Invitation-to-Partner-2013-6-201.pdf

15. Garrett, T. (2008). Student-Centered and Teacher-Centered Classroom Management: A Case Study of Three Elementary Teachers. Journal of Classroom Interaction, 43(1), 34-47. Retrieved from the Eric database.

16. Ghamrawi, N. (2010). No teacher left behind: Subject leadership that promotes teacher leadership. British Educational Leadership Management \& Administration Journal (EMAL), vol. 38, no. 3, p. 304-320, London: Sage.

17. Ghamrawi, N. (2012). The Relationship between the Leadership Styles of Lebanese Public Schools Principals and Their Attitudes towards ICT versus the Level of ICT Use By Their Teachers. Open Journal of Leadership, 2(1), 1-10. Retrieved January 15, 2015 from http://www.academia.edu

18. Ghamrawi, N. (2013). In Principle: It is not Only the Principal! Teacher Leadership Architectures in Schools. International Education Studies, 6(2) 1-12. Retrieved February 6, 2015 from http://www.academia.edu

19. Harris, A. T. (2010). Using Professional Learning Communities to Build Teacher Leadership Capacity: 
Creating Sustainable Change in Education. Retrieved from the Eric database.

20. International Baccalaureate Organization (IBO). (2008). IB learner profile booklet.

21. Lumpkin, A. (2016). Key characteristics of teacher leaders in schools. Administrative Issues Journal: Connecting Education, Practice, and Research, 4(2), 14

22. McCarthy, J. (2015). Student-centered learning: It starts with the teacher. Edutopia. Retrieved March 24, 2016.

23. Mizell, H. (2010). Why Professional Development Matters. Learning Forward. 504 South Locust Street, Oxford, OH 45056. Retrieved form the Eric database.

24. Northouse, P. G. (2013). Leadership: Theory and practice (6th ed.). Thousand Oaks, CA: Sage.

25. Overby, K. (2011). Student-Centered Learning. ESSAI, 9 (32) 1-5. Retrieved March 2, 2015 from http://dc.cod.edu/essai

26. Patton, C. M. (2015). Employing Active Learning Strategies to Become the Facilitator, Not the Authoritarian: A Literature Review. Journal of Instructional Research, 4, 134-141. Retrieved from the Eric database.

27. Phipher, J. (2002). Setting Up and Facilitating StudentCentered Classrooms. New York:Rowman and LittleField Education.

28. Pimenta, G., S. (2005). Critical-Collaborative Action Research: constructing its meaning Through experiences in teacher education. University of Sau Paulo. Received from the Eric database.
29. Razfar, A. (2011). Action research in urban schools: Empowerment, transformation, and challenges. Teacher Education Quarterly, 38(4), 25-44. Retrieved from the Eric database.

30. Schleicher, A. (2015). Schools for 21st-Century Learners: Strong Leaders, Confident Teachers, Innovative Approaches. International Summit on the Teaching Profession, OECD Publishing. Retrieved from Eric database.

31. Sergiovanni, J. T., \& Starrat, J., R. (2007). Supervision: A Redefinition. New York: Beth Mejia-McGraw-Hill.

32. Spillane, P. J., \& Diamond, B. J. (2007). Distributed Leadership in Practice. New York and London: Teachers College Press.

33. Wiederman, M. (2015). Active Learning and LearnerCentered Instruction. University of South Carolina School of Medicine Greenville. Retrieved February 14, 2015 from https://www.sc.edu/study/colleges_schools/medicine_greenvi lle/internal/documents/learner_centered_strategies.pdf

34. William, S. (2011). Engaging and informing students through group work. The British Psychological Society, 17(1), 24-34. Retrieved from the Eric database.

35. Xu, Y. \& Patmor, G. (2012). Fostering Leadership Skills in Pre-Service Teacher. International Journal of Teaching and Learning in Higher Education, 24(2), 1-5. Retrieved from the Eric database.

36. Yildirim, R. (2013). The Portfolio Effect Enhancing: Enhancing Turkish ELT Student-Teachers' Autonomy. Australian Journal of Teacher Education, 38(8), 92-110 Retrieved from the Eric database. 